\title{
Physiotherapy management of low back pain - a Review of Surveys
}

\begin{abstract}
Low back pain (LBP) is an increasingly debilitating and costly problem. One of the research focuses in LBP is an attempt to improve patient outcomes. It is believed that the promotion of evidence based practice (EBP) should improve patient outcomes and also reduce the cost of care. There seems to be a need to establish how physiotherapists manage LBP and whether management is in accordance with best practice based on published research evidence. The aim of this study was to determine what management strategies physiotherapists employ in the management of LBP by performing a review of the literature and to compare this with recent guidelines
\end{abstract}

Fourteen studies were included for the review. The treatments most frequently reported as being used for the management of LBP were education/ advice, exercise, spinal mobilisation and electrotherapy.

Over a 14 year period there were no major changes in the way physiotherapists manage LBP. Physiotherapist use interventions that are evidence based as well as interventions with little evidence in the management of LBP.

\section{KEY WORDS: LOW BACK PAIN, PHYSIOTHERAPY, SURVEY, INTERVENTIONS, EVIDENCE BASED PRACTICE.}

\section{INTRODUCTION}

Low back pain (LBP) is becoming an increasingly debilitating and costly problem, (Buchbinder et al 2001; Mannion et al 2001). The cost of LBP is a heavy burden for the health care systems of many countries (Koes et al 2006; Linton 1998). In the United States the prevalence and physician visits for LBP were approximately the same in 2002 as the previous decade (Deyo et al 2006).

The management of LBP has been described as a "twentieth century healthcare disaster" (Waddell 1996). Therefore one of the research focuses in the management of LBP is an attempt to improve patient care and outcomes (Parahoo 2000). This has resulted in an increased emphasis on EBP for the management of LBP. EBP practice is described as "the conscientious, explicit and judicious use of current best evidence in making decisions about the care of individual patients. The practice of evidence based medicine, means integrating individual clinical expertise with the best available clinical evidence from systematic research" (Sackett et al 1996 p72). It is believed that the promotion of EBP should both improve patient outcomes and reduce the cost of care (Borkan et al 2002; Iles \& Davidson 2006; Parahoo 2000).

Clinical guidelines have been developed to facilitate the use of EBP and the translation of evidence to clinical practice (Burton \& Waddell 1998; Koes et al 2001). Koes et al (2001) reviewed guidelines developed in different countries for the management of LBP and concluded that recommendations were similar across the board. Guidelines endeavour to guide decision making on the care of a condition using the best available research evidence (Borkan et al 2002; Koes et al 2001). The potential impact of guidelines on clinical practice is questionable unless supported by a well designed strategy to implement the guidelines into clinical practice (Borkan et al 2002). From the above there seems to be a need for information on existing physiotherapy management of LBP and to establish if guidelines have changed practice over time.

\section{AIM OF THE STUDY}

The aim of the study was to determine what interventions are used by physiotherapists in the management of LBP.
Furthermore to establish whether the actual management strategies concur with current best evidence as advocated in guidelines on the management of LBP. A review of the literature was conducted to answer the research question.

\section{METHOD}

Studies included were surveys or descriptive studies on the management of LBP by physiotherapists. Only studies describing treatment of LBP by physiotherapists were included.

The search was limited to studies published in English. An search of MEDLINE was undertaken followed by an analysis of the text words contained in the title and abstract and of the index terms used to describe the article.
Correspondence to:
Annalie Basson
BSc Physiotherapy (Stellenbosch)
MPhysT Research (Pretoria)
Private Practice
P.O. Box 74745
Lynnwood Ridge
0040
E-mail:annalieb@intekom.co.za 
A second search using all identified key words and index terms was then undertaken. The reference list of all identified articles was searched for additional studies. The initial search was conducted from January 1994 to November 2006 and identified 189 papers. In November 2008 the search was updated to include studies up to that date. Keywords used for the review were low back pain, survey and/or questionnaire, physiotherapist or physical therapy, physical therapy/ physiotherapy modalities.

\section{STATISTICAL ANALYSIS}

The study was primarily descriptive and the data of the findings were summarised describing the frequency at which an intervention was used as well as the mean percentage and standard deviation of the total number of times an intervention was used. Microsoft Excel 2003 was used to do the analysis.

\section{RESULTS}

The initial search (2006) yielded 189 studies. Fourteen studies were included in the analysis (See Table 1). The treatments most frequently reported as being used for the management of LBP were education/ advice (68\%), exercise (60\%) spinal mobilisation (51\%), electrotherapy (49\%), McKenzie (47\%) and hot packs/ heat (41\%). The intervention least used was manipulation (9.5\%).

Six of the fourteen studies had sub classification groups for LBP. The groups distinguished between acute LBP, sub acute LBP, LBP with radiating leg pain and chronic LBP. The other studies investigated non-specific LBP. There was no difference in the management of acute LBP and chronic LBP reported in any of the surveys (Li \& Bombardier 2001; Poitras et al 2005; Swinkels et al 2005; Strand et al 2005). The use of spinal mobilisation and some form of exercise were reported in all studies. Some techniques were only reported in a few studies such as shortwave diathermy (See Table 2).

\section{GUIDELINES ON THE MANAGEMENT OF LOW BACK PAIN}

A number of guidelines were reviewed for use to compare the results of the survey with guideline recommendations
(ACC 2004; Chou et al 2009; Bekkering et al 2003). It was decided to use the European LBP Guidelines (Airaiksinen et al 2006; Van Tulder et al 2006). These guidelines followed a rigorous process of development, are multidisciplinary and have guidelines for the management of acute and chronic LBP. For acute LBP (Van Tulder et al 2006) the guidelines recommend the following;

- Information and reassurance about the course and natural resolution of LBP

- Bed rest is not advised

- Return to normal activities

- Spinal manipulation /mobilisation if the patient is not recovering.

For chronic LBP the following is recommended (Airaiksinen et al 2006);

- Multidisciplinary treatment in an occupational setting

- The use of a cognitive behavioural therapy approach

- Supervised exercises tailored for the patient

- All treatment should be based on a bio psychosocial model

- Back schools

- A short course of mobilisation/ manipulations.

\section{DISCUSSION}

Advice and education were the interventions used most by physiotherapists in the management of LBP. However, specific advice to stay active as advocated by the guidelines for acute LBP was mentioned in only a few studies (Jackson 2001; Mikhail et al 2005; Reid et al 2002; Swinkels et al 2005; Strand et al 2005) Exercise was the second most used modality, however, exercise is not recommended in the management of acute LBP but for chronic LBP only. Mobilisation was used about 50\% of the time and this is in line with the guidelines recommendation for acute and chronic LBP. Manipulation was used by only $9.5 \%$ of physiotherapists in the management of LBP.

Despite the fact that acute and chronic LBP are two distinct entities there was no difference between the management of acute and chronic LPB in any of the studies that investigated both (Battie et al 1994; Casserley- Feeney et al 2008;
Swinkels et al 2005; Van der Valk et al 1995). Electrotherapy modalities such as interferential, ultrasound and hot packs were used almost a third of the time despite a lack of evidence for their use. Jackson (2001) asked physiotherapists why they used electrotherapy and one of the reasons given was "that they think it works". Perceived patient satisfaction/ expectations were also cited as a reason for the use of electrotherapy (Jackson 2001). The last reason stated for using electrotherapy (Jackson 2001) was the ability to treat a patient in a beneficial position. It is therefore possible that the use of electrotherapy is merely a way of achieving patient compliance and satisfaction. Foster et al (1999) argue that undergraduate training could contribute to the use of electrotherapy modalities as electrotherapy modalities are taught and therefore taken to be effective.

\section{CONCLUSION}

Although advice and education are used frequently it is not clear what this entails. Mobilisation, but not manipulation is used often which seems to comply with the recommendations of the guidelines. The fact that no distinction is made between the management of acute and chronic LBP is clearly an area that needs to be addressed.

Over a 14 year period there were no major changes in the way physiotherapists manage LBP. Despite more studies and the availability of excellent guidelines, modalities with little or no evidence as to their efficacy are still being used. There seems to be a need for improved transfer of research evidence to clinical practice. 
Table 1. Studies included for review.

\begin{tabular}{|l|l|l|}
\hline Authors & Type of study & Classification \& Type \\
\hline Jette et al 1994 & Physiotherapists notes retrospectively & LBP \\
\hline Battie et al 1994 & Survey & Acute, subacute, chronic \\
\hline Van der Valk et al 1995 & Survey & Acute, subacute, chronic \\
\hline Foster et al 1999 & Survey & LPB \\
\hline Li \& Bombardier 2001 & Survey & Acute, sub acute, radiating leg pain \\
\hline Jackson 2001 & Physiotherapists notes retrospectively & LBP \\
\hline Gracey et al 2002 & Survey & LBP \\
\hline Reid et al 2002 & Survey & Acute \\
\hline Pensri et al 2005 & Survey & LBP \\
\hline Mikhail et al 2005 & & LBP \\
\hline Strand et al 2005 & OMT students review treatment & LBP \\
\hline Poitras et al 2005 & Survey & Acute, sub acute, radiating leg pain \\
\hline Swinkels et al 2005 & Data basis retrospective & Acute, chronic non specific LBP \\
\hline Casserley-Feeney et al 2008 & Physiotherapists notes retrospectively & Acute, chronic LBP \\
\hline
\end{tabular}

Table 2. Treatments used by physiotherapists The average percentage of use, standard deviation (Std Dev) and frequency with which an intervention was reported in studies.

\begin{tabular}{|l|l|l|l|}
\hline Treatment & $\begin{array}{l}\text { Average } \\
\text { use in \% }\end{array}$ & Std Dev & $\begin{array}{l}\text { Frequency technique } \\
\text { was used in studies }\end{array}$ \\
\hline Education /Advice & 61.1 & 30.5 & 11 \\
\hline General exercises & 55.4 & 27.6 & 12 \\
\hline Stretching exercises & 51.7 & 38.3 & 6 \\
\hline Mobilisation & 48.3 & 25.1 & 14 \\
\hline Interferential & 35.7 & 29.5 & 6 \\
\hline Ultrasound & 30.8 & 28.3 & 8 \\
\hline Massage & 30.4 & 22.8 & 8 \\
\hline Hot packs & 29.3 & 24.9 & 8 \\
\hline McKenzie & 32.6 & 23.9 & 6 \\
\hline Traction & 18.9 & 17 & 10 \\
\hline Manipulation & 7.8 & 4.8 & 6 \\
\hline Stabilisation & 32.6 & 21.4 & 5 \\
\hline Electrotherapy & 53.3 & 35.3 & 3 \\
\hline Home Exercise & 63.6 & 28.7 & 4 \\
\hline
\end{tabular}

\section{REFERENCES}

Airaksinen O, Brox JI, Cedraschi C, Hildebrandt J, Klaber-Moffet J, Kovacs F, Mannion A, Reis S, Staal JB, Ursin H, Zanoli G (2006) European Guidelines for the management of chronic nonspecific low back pain. European Journal of Spine 15: S192 - S300.

Battie MC, Cherkin DC, Dunn R, Ciol MA, Wheeler KJ (1994). Managing low back pain: Attitudes and treatment preferences of physical therapists. Physical Therapy 74: $219-226$.

Bekkering GE, Hendriks HJM, Koes BW, Oostendorp RAB, Ostelo RWJG, Thomassen JMC, Van Tulder MW (2003). Dutch physiotherapy guidelines for low back pain Physiotherapy 89: $82-92$.

Bero LA, Grilli R, Grimshaw JM, Harvey E, Oxman AD, Thomson MA. (1998) Closing the gap between research and practice: an overview of systematic reviews of interventions to promote the implementation of research findings. British Medical Journal 317: 465 - 468.

Borkan J, Van Tulder M, Reis S, Schoene ML, Croft P, Hermoni D (2002). Advances in the field of low back pain in primary care. Spine 27: E128 $-\mathrm{E} 132$. 
Buchbinder R, Jolley D, Wyatt M (2001) Effects of a media campaign on back pain beliefs and its potential influence on management of low back pain in general practice. Spine 26: 2535 - 2542 .

Burton AK, Waddell G. (1998) Clinical guidelines in the management of low back pain. Baillieres Clinical Rheumatology $12: 17-35$.

Casserley-Feeney SN; Bury G; Daly L; Hurley DA (2008). Physiotherapy for low back pain: Differences between public and private healthcare sectors in Ireland - a retrospective survey. Manual Therapy 13: $441-449$.

Chou R, Loeser JD, Owens DK, Rosenquist RW, Atlas SJ, Baisden J, Carragee EJ, Grabois M, Murphy DR, Resnick DK, Stanos SP, Shaffer WO, Wall EM (2009). Interventional therapies, surgery, and interdisciplinary rehabilitation for low back pain. An evidence based clinical practice guideline from the American Pain Society. Spine 34: $1066-1077$.

Deyo RA, Mizra SK, Martin BI (2006) Back pain prevalence and visit rates. Spine 31: $2724-2727$.

Foster NE. Thompson KA. Baxter GD. Allen JM (1999). Management of non-specific low back pain by physiotherapists in Britain and Ireland: a descriptive questionnaire of current clinical practice. Spine1: 1332-42.

Gracey JH; McDonough SM; Baxter GD (2002). Physiotherapy management of low back pain. A survey of current practice in Northern Ireland. Spine 27: 406 -411.

Iles R, Davidson M (2006). Evidence based practice: a survey of physiotherapists' current practice. Physiotherapy Research International 11: $93-103$.

Jackson DA.(2001). How is low back pain managed? Retrospective study of the first 200 patients with low back pain referred to a newly established community-based physiotherapy department. Physiotherapy 87: pp 573-81.
Jette AM. Smith K. Haley SM. Davis KD. (1994). Physical therapy episodes of care for patients with low back pain. Physical Therapy. 74: 101 - 115.

Koes BW, Van Tulder MW, Ostelo R, Burton AK, Waddell G.(2001) Clinical guidelines for the management of low back pain in primary care: an international comparison. Spine 26: 2504 - 2514.

Koes BW, Van Tulder MW, Thomas S (2006) Diagnosis and treatment of low back pain. British Medical Journal 332: 1430 - 1434.

Li LI; Bombardier C (2001). Physical Therapy management of low back pain: An exploratory survey of therapist approaches. Physical Therapy 81: $1018-1028$

Linton SJ (1998). The socio-economic impact of chronic back pain: is anyone benefiting? Pain 75 : $163-168$.

Mannion F, Junge A, Tarmela S, Mûntener M, Lorenzo K, Dvorak J (2001). Part 3 Factors influencing Self-rated Disability and its change following Therapy. Spine 26: 920-929.

Mikhail C; Korner-Bitensky N; Rossignol M; Dumas J-P (2005). Physical therapist's use of interventions with high evidence of effectiveness in the management of a hypothetical typical patient with acute low back pain. Physical Therapy $85: 1151-1167$

New Zealand acute low back pain guide (2004) http://www.acc.co.nz/acc-publications/pdfs/ip/acc 05/09/2009.

Overmeer T, Linton SJ, Holmquist L, Eriksson M, Engfeldt P. (2004) Do evidence-based guidelines have an impact in primary care? A cross-sectional study of Swedish physicians and physiotherapists. Spine 30:146-151

Parahoo K (2000) Barriers to, facilitators of, research utilization among nurses in Northern Ireland. Journal of Advanced Nursing 31: 89 - 98

Pensri P; Foster NE; Srisuk S; Baxter GD; McDonough SM (2005). Physiotherapy management of low back pain in Thailand: a study of practice. Physiotherapy Research International 10: $201-211$.
Poitras S; Blais R; Swaine B; Rossignol (2005). Management of work-related low back pain: A population based survey of physical therapists. Physical Therapy 85: $1168-1180$.

Reid D. Larmer P. Robb G. Hing W. McNair $P$ (2002). Use of a vignette to investigate the physiotherapy treatment of an acute episode of low back pain: report of a survey of New Zealand physiotherapists. New Zealand Journal of Physiotherapy 30: 26-32.

Sackett DL, Rosenberg WMC, Gray JAM, Haynes RB, Richardson WS (1996) Evidence based medicine: what it is and what it isn't. BMJ 312: 71 - 72

Strand LI; Kvale A; Raheim M; Ljunggren AE (2005). Do Norwegian manual therapists provide management for patient with acute low back pain in accordance with clinical guidelines? Manual Therapy 10: $38-43$.

Swinkels ICS; Van den Ende CHM; Van den Bosch W; Dekker J; Wimmers RH (2005). Physiotherapy management of low back pain: Does practice match the Dutch guidelines? Australian Journal of Physiotherapy 51: $35-41$.

Van der Valk RWA; Dekker J; Van Baar ME (1995). Physical therapy for patients with low back pain. Physiotherapy 81: $345-351$.

Van Tulder M; Becker A; Bekkering T; Breen A; Gil del Real MT; Hutchinson A; Koes B; Laerum E; Malmivaara A (2006). European guidelines for the management of acute nonspecific low back pain in primary care. European Spine Journal 15 : S169-S191.

Waddell G. (1996). Keynote address for primary care forum. Low back pain: a twentieth century health care enigma. Spine 21: 2820 - 2825.

\section{REMEMBER WCPT CONGRESS 2011

